Journal of Current and Advance Medical Research

July 2018, Vol. 5, No. 2, pp. 64-67

http://www.banglajol.info/index.php/JCAMR

ISSN (Print) 2313-447X

ISSN (Online) 2413-323X

DOI: http://dx.doi.org/10.3329/jcamr.v5i2.37062

ORIGINAL ARTICLE OPEN 2 ACCESS

\title{
Clinical Profiles of Spontaneous Intracerebral Haemorrhage Patients: Experience of 100 Cases in Dhaka City
}

\author{
Md. Mamnur Rashid ${ }^{1}$, Md. Ariful Islam², Golam Sagir ${ }^{3}$, Md. Rafiqul Islam4, Muhammad \\ Abdul Momen Khan ${ }^{5}$, Farhana Moslehuddin ${ }^{6}$, Md. Badrul Alam ${ }^{7}$
}

\begin{abstract}
${ }^{1}$ Resident Physician, Department of Neurology, National Institute of Neurosciences \& Hospital, Dhaka, Bangladesh; ${ }^{2}$ Assistant Professor, Department of Neurology, National Institute of Neurosciences \& Hospital, Dhaka, Bangladesh; ${ }^{3}$ Junior Consultant, Department of Neurology, National Institute of Neurosciences \& Hospital, Dhaka, Bangladesh; ${ }^{4}$ Assistant Professor, Department of Pharmacology, National Institute of Neurosciences \& Hospital, Dhaka, Bangladesh; ${ }^{5}$ Assistant Professor, Department of Neurology, National Institute of Neurosciences \& Hospital, Dhaka, Bangladesh; ${ }^{6}$ Junior Consultant, Department of Neurology, National Institute of Neurosciences \& Hospital, Dhaka, Bangladesh; ${ }^{7}$ Professor, Department of Neurology, National Institute of Neurosciences \& Hospital, Dhaka, Bangladesh
\end{abstract}

[Received on: 1 March 2018; Reviewed on: 23 March 2018; Accepted on: 10 June 2018; Published on: 1 July 2018]

\section{Abstract}

Background: Clinical features are the important diagnostic tools for the detection of spontaneous intracerebral haemorrhage patients. Objective: The purpose of the present study was to see the clinical profiles of spontaneous intracerebral haemorrhage patients. Methodology: This cross-sectional study was conducted in the Department of Neurology at Dhaka Medical College and Hospital, Dhaka, Bangladesh from July 2012 to June 2014 for a period of two (2) years. Patients with spontaneous intracerebral haemorrhage who were admitted in the Departments of Neurology, Neurosurgery and Medicine at Dhaka Medical College and Hospital, Dhaka were selected as study population. Both male and female patients with the age group of $\geq 18$ years, first ever spontaneous intracerebral haemorrhage and hospital admission within 48 hours of onset were included for this study. The clinical features of the study population were collected after admission of the patients like headache, hemiplegia or paresis, vomiting, and deterioration of consciousness, dysphasia, dysarthria and hemisensory loss. Result: Headache was observed the most frequent complaint in $81.0 \%(\mathrm{n}=79)$ patients. Hemiparesis or hemiplegia was the most frequent focal neurological deficit in $69.0 \%(\mathrm{n}=68)$ patients. Vomiting was common also $58.0 \%(\mathrm{n}=57)$ patients. Twenty five $(26.0 \%)$ respondents were presented with deterioration of consciousness. Dysphasia/aphasia was found in $15.0 \%$ patients. Convulsion was not a common presenting feature (7\%). Conclusion: In conclusion headache, vomiting and deterioration of consciousness are the most common clinical feature of spontaneous intracerebral haemorrhage. [Journal of Current and Advance Medical Research 2018;5(2):64-67]

Keywords: Spontaneous intracerebral haemorrhage; clinical characteristics; stroke

Correspondence: Dr. Md. Mamnur Rashid, Resident Physician, Department of Neurology, National Institute of Neurosciecnes \& Hospital, Dhaka, Bangladesh; Email: dr.mrashidfmc@ gmail.com; cell no.: +8801711073653

Cite this article as: Rashid MM, Islam MA, Sagir G, Islam MR, Khan MAM, Moslehuddin F, Alam MB. Clinical Profiles of Spontaneous Intracerebral Haemorrhage Patients: Experience of 100 Cases in Dhaka City. J Curr Adv Med Res 2018;5(2):64-67

Funding: This study has been performed without any funding from outside else.

Conflict of Interest: There was no conflict of interest to any of the authors.

Contributions to authors: Rashid MM, Islam MA, Sagir G, Islam MR have contributed in protocol preparation, data collection, data analysis upto the report writing; Rashid MM, Khan MAM, Moslehuddin F, Alam MB have written \& revised the manuscript.

Copyright: O2018. Rashid et al. Published by Journal of Current and Advance Medical Research. This article is published under the Creative Commons CC BY-NC License (https://creativecommons.org/licenses/by-nc/4.0/). This license permits use, distribution and reproduction in any medium, provided the original work is properly cited, and is not used for commercial purposes. 


\section{Introduction}

Stroke due to intracerebral haemorrhage without any trauma and underlying lesion is known as spontaneous intracerebral haemorrhage ${ }^{1}$. Spontaneous intracerebral hemorrhage (sICH) occurs as non-traumatic and without any underlying lesion which is often a devastating clinical event with limited effective therapies ${ }^{2}$. It accounts for approximately 10.0 to $15.0 \%$ of all strokes ${ }^{3}$. It presents with sudden focal neurological deficit or reduced level of consciousness after which it kills about half of those affected within one month and leaves most survivors disabled ${ }^{4}$. Case fatality has not been changed in spontaneous ICH over the past few decades ${ }^{5}$.

Spontaneous ICH associated with hypertension and amyloid angiopathy, is grouped as primary intracerebral haemorrhage ${ }^{6}$. Other causes of spontaneous ICH are vascular malformations, vasculitic disorders, Moyamoya disease, tumour haemorrhages, haemorrhagic infarcts, haemorrhagic diathesis and those associated with use of anticoagulant or fibrinolytic drugs ${ }^{7}$. Stroke clearly ranks first among all the neurologic diseases of adult, both in frequency and importance. At least half of the patients with a neurologic disorder attending general hospitals suffer from stroke ${ }^{8}$. Though intracerebral haemorrhage (ICH) accounts for approximately $10-20 \%$ of strokes, its importance derives from high mortality that varies between $25 \%$ to $60.0 \%{ }^{9}$. The purpose of the present study was to see the clinical profiles of spontaneous intracerebral haemorrhage patients.

\section{Methodology}

This cross-sectional study was conducted in the Department of Neurology at Dhaka Medical College and Hospital, Dhaka, Bangladesh from July 2012 to June 2014 for a period of two (2) years. Patients with spontaneous intracerebral haemorrhage who were admitted in the Departments of Neurology, Department of Neurosurgery and Department of Medicine, at Dhaka Medical College and Hospital, Dhaka were selected as study population. Spontaneous intracerebral haemorrhage was defined as neurological deficit documented by a brain CT indicating the presence of an intracerebral hemorrhage in absence of trauma or surgery. Both male and female patients with the age group of $\geq 18$ years, first ever spontaneous intracerebral haemorrhage and hospital admission within 48 hours of onset were included for this study. Patients with haematoma secondary to head injury, patients of ischaemic stroke and subarachnoid haemorrhage, patients underwent surgical or interventional procedure, unable to confirm by CT scan of head or serious co-morbidity like chronic kidney disease, heart failure, decompensated chronic liver disease, respiratory failure and metabolic encephalopathy and infection were excluded from this study. Patients having SICH were detected with the help of CT-scan of head. Patients with ischemic stroke were excluded. Those with sICH were selected for the study, after getting the informed consent. The clinical features of the study population were collected after admission of the patients like Headache, hemiplegia/paresis, vomiting, deterioration of consciousness, dysphasia or aphasia, dysarthria, behavioural abnormalities, convulsion, monoparesis and hemisensory loss. A detailed history was taken and a meticulous neurological examination was performed in every patient. CT scan of head was done on every patient at the department of radiology and imaging of Dhaka Medical Collegeas early as possible for confirmation of spontaneous intracerebral hemorrhage. Data was taken from patient or attendant and medical record of the patient. The analyses were performed manually using standard statistical procedures. SPSS version 20 were utilized whenever required and also to cross-check the results. Prior to the commencement of this study, the research protocol was approved by the Research Review Committee.

\section{Result}

A total number of 98 patients were included for this study after fulfilling the inclusion and exclusion criteria. Eighty two (84\%) patients of the study subjects were more than 50 years of age. The youngest and eldest subjects aged 20 and 80 years, respectively. Mean ( \pm standard deviation) age was $64.01 \pm 13.90$ years $($ Table 1$)$.

\section{Table 1: Age Distribution of the Study Population $(\mathbf{n = 9 8})$}

\begin{tabular}{|l|c|c|}
\hline Age Group & Frequency & Percentage \\
\hline Less than 20 Years & 1 & 1.02 \\
\hline 21 to 40 Years & 8 & 8.2 \\
\hline 41 to 60 Years & 23 & 23.4 \\
\hline More than 60 Years & 66 & 67.3 \\
\hline Total & $\mathbf{9 8}$ & $\mathbf{1 0 0 . 0}$ \\
\hline
\end{tabular}

Table 2 shows the presenting features of the patients with spontaneous intracerebral haemorrhage. Headache was observed the most frequent complaint in $81 \% \quad(\mathrm{~N}=79)$ patients. Hemiparesis/Hemiplegia was the next common 
presenting feature and most frequent focal neurological deficit in $69 \% \quad(n=68)$ patients. Vomiting was common also 58\% $(\mathrm{n}=57)$ patients. Twenty five (26\%) respondents were presented with deterioration of consciousness. Dysphasia/aphasia was found in $15 \%$ patients. Convulsion was not a common presenting feature, found in $7 \%$ respondents.

Table 2: Distribution of the Presenting Features of the Respondents ( $n=98)$

\begin{tabular}{|l|c|c|}
\hline $\begin{array}{l}\text { Feature } \\
\text { Headache }\end{array}$ & 79 & 80.61 \\
\hline $\begin{array}{l}\text { Hemiplegia/paresis } \\
\text { Vomiting }\end{array}$ & 68 & 69.38 \\
\hline $\begin{array}{l}\text { Deterioration of } \\
\text { consciousness }\end{array}$ & 25 & 58.16 \\
\hline $\begin{array}{l}\text { Dysphasia/ } \\
\text { aphasia }\end{array}$ & 15 & 15.30 \\
\hline $\begin{array}{l}\text { Dysarthria } \\
\text { Behavioural } \\
\text { abnormalities }\end{array}$ & 11 & 11.22 \\
\hline \begin{tabular}{l} 
Convulsion \\
\hline Monoparesis
\end{tabular} & 7 & 10.20 \\
\hline Hemisensory loss & 2 & 7.14 \\
\hline *Multiple responses & & 3.06 \\
\hline
\end{tabular}

\section{Discussion}

There are several risk factors of spontaneous ICH. Hypertension is the most important risk factor for spontaneous ICH and the contribution of hypertension is greater for deep ICH than for lobar $\mathrm{ICH}^{10}$. Current smoking and heavy alcohol consumption are associated with increased risk of ICH. An Australian case-control study showed an inverse relationship between cholesterol level and the risk of $\mathrm{ICH}^{11}$. Another study found that low total cholesterol and Low-density lipoprotein cholesterol levels were associated with more severe $\mathrm{ICH}^{12}$. The use of warfarin increases the risk of ICH by two- to five-fold, depending upon the intensity of anticoagulation ${ }^{13}$. Anticoagulation-related ICH is nowadays increasing because of the increased use of oral anticoagulation in elderly population ${ }^{14}$. Antiplatelet therapy can increase the risk of ICH. Several case-control studies did not show an increased ICH risk with antiplatelet use; however, meta-analyses showed that antiplatelet therapy was associated with a small but significant increase in the ICH risk ${ }^{11}$. In addition, a meta-analysis showed that prior antiplatelet use was associated with an increased risk of death after the ICH and another studies demonstrated an increased risk of early hematoma growth with prior antiplatelet use ${ }^{15}$. In particular, dual antiplatelet therapy compared to antiplatelet monotherapy is likely to further increase the ICH risk. In patients with atrial fibrillation, the risk of ICH is almost twice as high with aspirin plus clopidogrel compared to aspirin alone ${ }^{12}$.

Ninety eight patients of spontaneous intracerebralhaemorrhage (ICH) were included in this study. Most $(84 \%)$ of the patients were of 50 years or more age. Mean ( \pm standard deviation) age was $64.01 \pm 13.90$ years. The age distribution was similar to that of most of the previous studies conducted in Bangladesh and India ${ }^{16-17}$. The youngest and oldest patients were of 20 and 80 years respectively. Number of males $(60 \%)$ was more than that of females (40\%) (M/F,1.50). Similar sex distribution was found in the study on spontaneous ICH patients in Heerlen, Netherlands ${ }^{18}$.

Headache was the most frequent presenting feature in $81.0 \%$ followed by hemiparesis/plegia in $70.0 \%$, vomiting in $58.0 \%$ and deteriorated consciousness observed in $26.0 \%$ patients. Convulsion was not a common presenting feature, found in $7.0 \%$ patients. Siddique ${ }^{16}$ and Al-Dahhan ${ }^{19}$ found similar results in spontaneous intracerebral haemorrhage, though proportion of patients presenting with deteriorated consciousness was lower in this study. Less severe initial presentation of the respondents might explain this discrepancy.

Although some individuals develop ICH during exertion or sudden emotional stress, most ICHs occur during routine activity. The neurologic symptoms usually aggravate over minutes or a few hours. The most common site of ICH is the putamen, and clinical presentations vary by the size and location of $\mathrm{ICH}^{10}$. Common ICH symptoms are headache, nausea, and vomiting. Headache is more common in patients with large hematomas, and is attributed to traction on meningeal pain fibers, increased intracranial pressure, or blood in the cerebrospinal fluid. Small, deep hematomas are rarely associated with headache. Vomiting is reported in about $50 \%$ of patients with hemispheric $\mathrm{ICH}$, and more common in patients with cerebellar hemorrhages. It is usually associated with increased intracranial pressure. Patients with large ICH often have a decreased level of consciousness due to increased intracranial pressure and compression of the thalamus and brainstem. Stupor or coma indicates large ICHs that involve the brainstem reticular activating system ${ }^{16}$. Seizures reported in about $10.0 \%$ of patients with ICH and about $50 \%$ of patients with lobar hemorrhage. Seizures typically 
occur at the onset of bleeding or within the first 24 hours ${ }^{11}$.

Neurological deterioration is common before and during hospital admission and may indicate early hematoma enlargement or worsening of edema ${ }^{1}$. Patients with a supratentorial ICH involving the basal ganglia or thalamus have contralateral sensorimotor deficits. Lobar hemorrhages may present with symptoms of a higher cortical dysfunction such as aphasia, neglect, gaze deviation, and hemianopia. In patients with an infratentorial ICH, signs of brainstem dysfunction occur such as ocular motor or other cranial nerve abnormalities, and contralateral motor deficits ${ }^{2}$. More than $40.0 \%$ of patients with CAA-associated ICH have some degree of cognitive dysfunction, and the cognitive changes may precede the ICH in some cases ${ }^{15}$.

\section{Conclusion}

In conclusion headache is the most common presentation of spontaneous ICH. Vomiting is also reported in a large number of patients. Furthermore, deterioration of consciousness is also a very important clinical feature of spontaneous $\mathrm{ICH}$. Moreover hemiplegia or paresis, dysphasia or aphasia and dysarthria are also reported in majority of the patients. Further large scale study in multicentre basis should be carried out.

\section{References}

1. Pendelbury ST, Matthew FG, Rothwell, PM. Epidemiology, risk factors, pathophysiology and causes of transient ischemic attacks and stroke. Transient ischemic attack and stroke. Cambridge University Press, Cambridge 2009;1-10

2. Godoy DA, Piñero G, Di Napoli M. Predicting Mortality in Spontaneous Intracerebral Hemorrhage. Stroke. 2006;37(4):1038-44

3. Dennis MS, Burn JP, Sandercock PA, Bamford JM, Wade DT, Warlow CP. Long-term survival after first-ever stroke: the Oxfordshire Community Stroke Project. Stroke. 1993;24(6):796-800

4. Salman RA, Lobovitz D, Stapf C. Spontaneous intracerebral hemorrhage. British Medical Journal 2009;39:284-289

5. Van BJ, Lovelock CE, Cordonnier C, Rothwell P, Clijin CI, Salman A. Outcome after spontaneous and arteriovenous malformation-related intracerebral hemorrhage: population based studies. Brain 2009;132(2):537-543
6. Hill MD, Silver FL, Austin PC, Tu JV. Rate of stroke recurrence in patients with primary intracerebral haemorrhage. Stroke 2000;31(1):123-127

7. Zia E, Engström G, Svensson PJ, Norrving B, PessahRasmussen H. Three-year survival and stroke recurrence rate in patients with primary intracerebral haemorrhage. Stroke 2009;40(11):3567-3573

8. Rooper, AH, Samuels, MA. Adams and Victors's principles of neurology, McGraw-Hill Medical Publishing Division, New York, 2009;802-808

9. Kase CS. Vascular diseases of the nervous system: Intracerebral hemorrhage' in Bradley, WB, Daroff, RB, Fenichel, GM \& Jankovic J (eds), Neurology in clinical practice, vol. II, Elsvier, Philadelphia, 2008

10. Martini SR, Flaherty ML, Brown WM, Haverbusch M, Comeau ME, Sauerbeck LR, et al. Risk factors for intracerebral hemorrhage differs according to hemorrhage location. Neurology. 2012;79:2275-2282

11. Grønbaek H, Johnsen SP, Jepsen P, Gislum M, Vilstrup H, TageJensen U, et al. Liver cirrhosis, other liver diseases, and risk of hospitalisation for intracerebral haemorrhage: a Danish population-based case-control study. BMC Gastroenterol. 2008;8:16

12. Mustanoja S, Strbian D, Putaala J, Meretoja A, Curtze S, Haapaniemi E, et al. Association of prestroke statin use and lipid levels with outcome of intracerebral hemorrhage. Stroke. 2013;44:2330-2332

13. Flaherty ML, Kissela B, Woo D, Kleindorfer D, Alwell K, Sekar P, et al. The increasing incidence of anticoagulantassociated intracerebral hemorrhage. Neurology 2007;68:116121

14. García-Rodríguez LA, Gaist D, Morton J, Cookson C, González-Pérez A. Antithrombotic drugs and risk of hemorrhagic stroke in the general population. Neurology 2013;81:566-574

15. Naidech AM, Jovanovic B, Liebling S, Garg RK, Bassin $\mathrm{SL}$, Bendok BR, et al. Reduced platelet activity is associated with early clot growth and worse 3-month outcome after intracerebral hemorrhage. Stroke 2009;40:2398-2401

16. Siddique MA, Nur Z, Mahbub MS, Alam MB, Miah MT. Clinical presentation and epidemiology of stroke: a study of 100 cases. Journal of Medicine. 2009;10(2):86-9.

17. Mohammad QD, Habib M, Hoque A, Alam B, Haque B, Hossain S, Rahman KM, Khan SU. Prevalence of stroke above forty years. Mymensingh medical journal: MMJ. 2011 Oct;20(4):640-4

18. Franke CL, Van Swieten JC, Algra A, Van Gijn J. Prognostic factors in patients with intracerebral haematoma. Journal of Neurology, Neurosurgery \& Psychiatry. 1992 Aug $1 ; 55(8): 653-7$

19. Morgenstern LB, Hemphill JC, Anderson C, Becker K, Broderick JP, Connolly ES, Greenberg SM, Huang JN, Macdonald RL, Messé SR, Mitchell PH. Guidelines for the management of spontaneous intracerebral hemorrhage. A guideline for healthcare professionals from the American Heart Association/American Stroke Association. Stroke. 2010 Jul 22 